\title{
STRATEGI PROMOSI DALAM PENINGKATAN JUMLAH MAHASISWA BARU FAKULTAS ILMU SOSIAL DAN ILMU POLITIK UNIVERSITAS MUHAMMADIYAH MATARAM
}

\author{
Ibrahim Abdullah, Lubis \\ Fakultas IImu Sosial dan Politik, Universitas Muhammadiyah Mataram, \\ Ibrahim.abdullah@gmail.com
}

\begin{tabular}{l} 
INFO ARTIKEL \\
\hline Riwayat Artikel: \\
Diterima: 20 - 04 - 2018 \\
Disetujui: 28 - 06- 2018
\end{tabular}

\section{Kata Kunci:}

Strategi

Promosi

Mahasiswa

Fisipol

\section{A. LATAR BELAKANG}

Indonesia sebagai negara berkembang sangat memperhatikan dan terus mengupayakan peningkatan kualitas Sumber Daya Manusia (SDM) yang salah satunya dilakukan melalui jalur pendidikan.Pendidikan sebagai suatu upaya untuk mencerdaskan kehidupan bangsa diharapkan mampu memberikan peran dan andil dalam akselarasi pembangunan.Pembangunan bidang pendidikan merupakan bagian tidak terpisahkan dari pembangunan nasional, karena memiliki posisi yang sangat strategis, mendasar dan potensial terutama untuk pembangunan Sumber Daya Manusia (SDM). Sumber Daya inilah yang nanti akan sangat menentukan kelestarian dan kejayaan bangsa dimasa yang akan datang. Oleh karena itu, pendidikan harus mampu memberikan kontribusi yang nyata terhadap pembangunan.

Pemasaran atau promosi menjadi suatu yang mutlak harus dilaksanakan oleh perguruan tinggi, selain ditujukan untuk memperkenalkan, funngsi pemasaran dilembaga pendidikan adalah untuk memperkenalkan, fungsi pemasaran dilembaga pendidikan adalah untuk membentuk citra baik terhadap lembaga dan menarik minat sejumlah calon mahasiswa.

Dengan promosi, perguruan tinggi dapat memperkenalkan diri dan menambah keyakinan masyarakat akan informasi yang ditawarkan oleh lembaga. Oleh karena itu, perguruan tinggi harus berusaha untuk dapat menghasilkan produk (mahasiswa) yang berkualitas karena dengan adanya produk yang berkualitas, layanan yang memuaskan dan didukung dengan promosi yang maksimal maka hasil yang diharapkan akan tercapai.

Universitas Muhammadiyah Mataram merupakan salah satu lembaga pendidikan swasta yang banyak diminati masyarakat dan memiliki dosen-dosen yang profesional yang sesuai dengan disiplin ilmunya masingmasing.Universitas Muhammadiyah Mataram merupakan perguruan tinggi swasta yang memiliki beberapa Fakultas dan program studi yang salah satunya 
adalah Fakultas FISIP yang memiliki mahasiswa yang tiap tahun berasal dari berbagai Daerah.

Lebih lengkapnya akan disajikan dalam tabel berikut ini :

TABEL 1.

Jumlah Mahasiswa Fisipol Universitas Muhammadiyah Mataram Tahun Akademik 2011-2013 Berdasarkan Validasi

\begin{tabular}{|c|c|c|c|c|c|c|c|}
\hline \multicolumn{8}{|c|}{ Dari } \\
\hline \multirow{2}{*}{ No } & Program & \multicolumn{2}{|c|}{2014} & \multicolumn{2}{|c|}{2015} & \multicolumn{2}{|c|}{2016} \\
\hline & Studi & $\mathrm{R}$ & NR & $\mathrm{R}$ & NR & $\mathrm{N}$ & $\mathrm{NR}$ \\
\hline \multirow{3}{*}{1} & Ilmu & & & & & & \\
\hline & Administrasi & & & & & & \\
\hline & Publik & 57 & 57 & 40 & 38 & 65 & 35 \\
\hline \multirow[t]{3}{*}{2} & Ilmu & & & & & & \\
\hline & Administrasi & & & & & & \\
\hline & Bisnis & 45 & 14 & 63 & 27 & 45 & 37 \\
\hline \multirow[t]{2}{*}{3} & Ilmu & & & & & & \\
\hline & Pemerintahan & 58 & 18 & 55 & 6 & 53 & 30 \\
\hline \multirow[t]{2}{*}{4} & D-3 & & & & & & \\
\hline & Perpustakaan & 38 & - & 73 & - & $\begin{array}{l}47 \\
312\end{array}$ & - \\
\hline \multicolumn{2}{|c|}{ Jumlah Total } & 287 & 89 & 302 & 71 & 102 & \\
\hline
\end{tabular}

Sumber : Kepala Biro Adm. Akademik UMM, 2017

Keterangan:

$\mathrm{R}=$ Reguler

$\mathrm{NR}=$ Non Reguler

Berdasarkan tabel diatas Fakultas FISIP yang terdiri dari empat program studi, pada tahun 2014 Fakultas FISIP memperoleh mahasiswa 287 orang, pada tahun 2015 memperoleh peningkatan mahasiswa sebanyak 302 orang dan begitupun pada tahun 2016 dengan jumlah mahasiswa 312 orang. Maka kita dapat melihat dari tabel 1.1 FISIPOL Universitas Muhammadiyah Mataram mengalami peningkatan mahasiswa setiap tahunnya secara signifikan. Berdasarkan dari latar belakang tersebut penulis tertarik untuk melakukan penelitian dengan judul "strategi promosi dalam peningkatan jumlah mahasiswa baru FISIPOL Universitas Muhammadiyah Mataram”.

\section{B. METODE PENELITIAN}

\section{Lokasi Penelitian dan Subjek Penelitian}

Lokasi penelitian merupakan tempat dimana proses penelitian berlangsung. penelitian ini dilakukan pada Fakultas Ilmu Sosial Dan Ilmu Politik Universitas Muhammadiyah Mataram. Peneliti berkeinginan untuk mengetahui Strategi Promosi Dalam Peningkatan Jumlah Mahasiswa FISIPOL Universitas Muhammadiyah Mataram 2016/2017.

\section{Teknik Pengumpulan Data}

Adapun teknik pengumpulan data yang digunakan penelitian ini adalah sebagai berikut:

a. Wawancara

Wawancara merupakan teknik pengumpulan data primer dan sekunder dengan cara melakukan tanya jawab secara langsung kepada pihak-pihak yang bersangkutan. Secara umum metode wawancara berstruktur yaitu pewawancara menggunakan daftar pertanyaan yang sudah dirumuskan dengan jelas.Metode ini, peneliti gunakan untuk memperoleh data tentang strategi promosi.Dalam penelitian ini digunakan wawancara terstruktur yang diberikan kepada pihak-pihak yang terkait ditujukan kepada staf-staf yang berkaitan dalam bidang promosi. (Sugiyono, 2009: 140).

b. Dokumentasi

Dokumentasi merupakan tehnik pengumpulan data yang dilakukan dengan cara melihat berkas, catatan, dan dokumen lain yang terdapat dalam perusahaan yang berkaitan dengan obyek penelitian. (Sugiyono, 2009: 240).

c. Observasi

Suharsimi Arikunto mengatakan bahwa observasi atau yang disebut pula dengan pengamatan meliputi kegiatan pemuatan terhadap suatu objek dengan menggunakan seluruh alat indra.Metode ini peneliti gunakan untuk pengamatan secara langsung mengenai pelaksanaan strategi promosi yang dilaksanakan di kampus.

\section{HASIL DAN PEMBAHASAN}

1. Gambaran umum Objek Penelitian

a. Sejarah Berdirinya Fakultas FISIPOL

Fakultas ilmu social dan ilmu politik universitas muhammadiyah mataram ( Fisipol UM . Mataram ) Didirikan bersamaa dengan 3 Fakultas lainnya di lingkungan Universitas MUhammadiyah Mataram pada tahun 1980 , yang dikelolah oleh Yayasan perguruan tinggi Muhammadiyah Mataram . Dengan akte Notaris Abdulrahim , SH No.335/1981 tanggal 24 Oktober 1981, kemudian di perbaharui dengan Akte Notaris Abdurrahim ,SH No 16/1986. peresmian berdirinya Fakultas Ilmu Sosial Dan ilmu Politik Universitas Muhammadiyah Mataram ditandai dengan perolehan Status terdaftar dari Dirjen Dikti Depdiknas No. 017/O/1982 tanggal 10 Mei 1982, bersamaan dengan itu juga diangkat dekan pertama yaitu Drs. Arifin.

Dalam perkembangan selnjutnya , Fakultas ini memperoleh Status diakui darai Dirjen Depdikns dnegan Nomor 0350/1991 tanggal 19 juni 1991, kemudian memperoleh Status terakriditasi dari badan Akreditas Nasional Perguruan Tinggi (BAN-PT) Nomor: 0213/AKII/UM81AN/X111998 untuk program studi Ilmu Administrasi Negara ,Nomor : 021228/AkII.I/UM81SN/XII/1998, untuk program studi Aministrasi Bisnis, dan Nomor : O213/Ak-II.I/UM81MA/XII/1998 untuk program studi ilmu pemerintahan dan pada tanggal 22 Desember 1998 , Pada awalnya hanya memiliki 3 program studi, kemudian bertambah menjadi 5 program studi yaitu tambahan program D3 ilmu perpustakaan pada tahun 
2002 dan Program perpustakaan Syariah tahun 2003 .

b. Visi Misi dan Tujuan Fakultas FISIPOL

1) Visi

Visi Fakultas ilmu social dan ilmu Politik (FISIP) adalah menjadi Fakultas yang uggul dalam pendidikan bertaraf Nasional dengan Pengembangan Ilmu pengetahuan Sosial dan Politik yang berlandaskan Al-Qur'an Dan Sunah Ashahihah.

2) Misi

a) Menyelengarakan pendidiakn bagi mahasiswa dan menghasilkan Alumni yang berkualifikasi Nasional

b) Menyelengarakan kegiatan untuk mengembangan Ilmu Sosial Dan Ilmu Politik yang berlandaskan Nilai- Nilai ke- Islaman yang bermanfaat bagi masyaraklat

c) Menyelengarakan kegiatan pelayanan dan pengambdian ke pada Masyarakat Sebagai bentuk pengaplikasian Ilmu pengetahuan dan untuk membantu memecahkan persoalan kebutuhan Masyarakat

3) Tujuan

a) Menghasilakan sarjana FISIP yang berstandar nasional

b) Mewujudkan sarjana yang menguasai pengetahuan dibidangnya dengan standar pendidikan dalam negri.

c) Mewujudkan sarjana yang memiliki keterampilan dalam bidang politik, Administrais dan menejemen publik, ilmu ekonomi, digital library dan perpustakaan online serta entrepreneurship

d) Menghasilakan sarjana yang memilik komitmen dalam pengalaman agama islam .

e) Mewujudkan sarjana yang menguasai teknologi informasi

f) Mewujudkan sarjana bermampuan bahasa inggris aktif dan pasif

g) Menghasilakan sarjana yang mampu menjawab persoalan di masyarakat

h) Meningkatkan kualitas dosen dan karyawan

i) Meningkatkan karya akademik dosen

j) Memacu terciptanya jabatan akademik dosen yang tinggi .

k) Meningkatkan tingkat pendidikan,keterampilan, serta kompetensi karyawan

l) Meningkatkan kesejahtera dosen dan karyawan

m) Mengadakan dan melengkapi sarana dan prasarana serta fasilitas

n) Melengkapi sarana laboratorium

o) Melengkapi sarana dan fasilitas ruang referensi

p) Menambah daftar koleksi perpustakaan fakultas

q) Menambah dan melengkapi sarana fasilitas ruang kelas r) Menambah dan melengkapi sarana dan fasilitas ruang ujian

s) Melengkapi fasilitas ruang dosen

t) Meningkatkan kualitas proses akademik

u) Menumbuhkan kultur akademik

v) Meningkatkan kualitas penelitian

w) Menambahkan kualitas pengabdian pada masyarakat

x) Mengembangkan kajian bidang ilmu social dan politik, administrasi dan manajemen public, ilmu ekonomi, digital library dan perpustakan online serta entrepreneurship yang berlandaskan nilai-nilai keislaman

y) Memantapkan system manajemen organisasi fakultas

z) Memperkuat kepemimpinan di tingkat fakultas

aa)Meningkatkan kualitas perencanaan, pelaksanaan, dan evaluasi program

bb) Meningkatkan kualitas pelayanan administrasi fakultas

4) Tugas pokok

a) Kepemimpinan mampu memprediksi masa depan, merumuskan dan mengartikulasi visi yang realistic, kredibel, serta mennkomunikasikan visi ke depan, yang menekankan pada keharmonisan hubungan manusia dan mampu menstimulasikan secara intelektual dan arif bagi anggota untuk mewujudkan visi, misi, dan tujuan organisasi, serta mampu memberikan arahan, tujuan, peran, dan tugas kepada seluruh unsure dalam perguruan tinggi.

b) Deskripsi Jurusan/Program studi di Fakultas FISIPOL

(1) Program Studi Ilmu Administrasi Bisnis

Program Studi Ilmu Administrasi Bisnis merupakan salah satu program Studi dilingkungan jurusan Ilmu administrasi Fakultas Ilmu Sosial dan Ilmu politik universitas muhammadiyah mataram . Program studi ini terdaftar Diparetemn Kementrian Pendidikan Nasional melalui keputusan Direktur Jendral Pendidikan Tinggi dan Selanjutnya memperoleh perpanjangan izin berdasarkan surat Koordinator Kopertis wilayah Nomor : 1779/D/T/K. VIII/2010 Tanggal 8 April 2010 dan terakditasi B keputusan Badan Akreditasi Nasional Nomor ; 002/BAN-PT/AkXIV/SI/V/2011 tanggal 13 Mei 2011. Berdasarkan surat keputusan Rektor Nomor

82//II.3AU/KEP/A/III/2O12

Tanggal 10 Maret 2012, bahwa sejak tanggal 10 Maret 2012 Program Studi Administrasi Niaga diubah nemonklaturnya menjadi program studi ilmu adminitrasi bisnis. 
(2) Program Studi Administrai Negara Program Studi Ilmu Administrasi Bisnis merupakan salah satu program Studi dilingkungan jurusan Ilmu administrasi Fakultas Ilmu Sosial dan Ilmu politik universitas muhammadiyah mataram . Program studi ini terdaftar Diparetemn Kementrian Pendidikan Nasional melalui keputusan Direktur Jendral Pendidikan Tinggi dan Selanjutnya memperoleh perpanjangan izin berdasarkan surat Koordinator Kopertis wilayah Nomor : 1406/D/T/K.VII/2010 Tanggsl 17 February 2010 dan Terakdimitasi berdasarkan SK. BAN-PT Nomor : 023/BAN-PT/Ak-XIV/SI/IX/2011

Tanggal 9 September 2011.

(3) Jurusan Administrasi Pemerintahan Program Studi Ilmu Administrasi Bisnis merupakan salah satu program Studi dilingkungan jurusan Ilmu administrasi Fakultas Ilmu Sosial dan Ilmu politik universitas muhammadiyah mataram . Program studi ini terdaftar Diparetemn Kementrian Pendidikan Nasional melalui keputusan Direktur Jendral Pendidikan Tinggi dan Selanjutnya memperoleh perpanjangan izin berdasarkan surat Koordinator Kopertis wilayah VII Nomor : 1407/D/T/K.VIII.2010 Tanggal 17 February 2010 dan terakreditas C, melalui keputusan Badan Akreditasi Nasional Nomo : 003/BAN-PT/Ak$\mathrm{XIV} / \mathrm{SI} / \mathrm{V} / 2011$

(4) Jurusan D3 Perpustakaan

Program Studi Ilmu Administrasi Bisnis merupakan salah satu program Studi dilingkungan jurusan Ilmu administrasi Fakultas Ilmu Sosial dan Ilmu politik universitas muhammadiyah mataram . Program studi ini terdaftar Diparetemn Kementrian Pendidikan Nasional melalui keputusan Direktur Jendral Pendidikan Tinggi dan Selanjutnya memperoleh perpanjangan izin berdasarkan surat Koordinator Kopertis wilayah VII Nomor : 9938/D/T/K-VII/2011 tanggal 828 Desember 2011 dan terakditasi C, melalui keptususan Badan Akreditasi Nasional Nomor: 026/BAN-PT/Ak-X/Dpl-

III/XII/2010 tangal 23 Desember 2010.

TABEL 2.

Dosen Fisip

\begin{tabular}{llllllll}
\hline \multicolumn{2}{c}{ Jabatan Akademik } & \multicolumn{3}{c}{$\begin{array}{c}\text { Pendidikan } \\
\text { Akhir }\end{array}$} & \multicolumn{2}{c}{ Total } \\
\hline $\begin{array}{l}\text { Lektor } \\
\text { Kepala }\end{array}$ & Lektor & $\begin{array}{c}\text { Asisten } \\
\text { Lektor }\end{array}$ & S1 & S2 & S3 & S3 & 64 \\
\hline
\end{tabular}

2

11

19

222

5

5) Price (biaya)

Unsur bauran pemasaran yang penting lainya adalah harga yang merupakan jumlah uang yang harus dibayar oleh konsumen untuk mendapatkan suatu produk. Biaya yang dikeluarkan untuk bisa masuk ke Fakultas FISIP cukup ekonomis dibandingkan dengan tempat lain seperti berikut:

TABEL 3.

Perbedaan Biaya Kuliah Mahasiswa Baru Dari Berbagai Universitas Swasta Di Mataram

\begin{tabular}{|c|c|c|c|c|c|}
\hline No & Universitas & $\begin{array}{c}\text { Pendaftaran } \\
\text { ulang }\end{array}$ & SPP & $\begin{array}{c}\text { Sumbangan } \\
\text { pembangunan }\end{array}$ & Jumlah \\
\hline 1. & UM.Mataram & 975juta & 1,5 juta & 38oribu & 2,855 juta \\
\hline 2. & Amikom & 2,42 juta & 2,45 juta & 1,5 juta & $6,37 j u t a$ \\
\hline 3. & STIE AMM & 2,1 juta & 1juta & $1,85 j u t a$ & 4,95juta \\
\hline
\end{tabular}

6) Place (Lokasi)

Place biasanya diterjemahkan sebagai saluran pemasaran. Saluran pemasaran adalah serangkian organisasi yang saling tergantung dan tidak terlibat dalam proses untuk menjadikan produk atau jasa siap untuk digunakan atau di konsumsi

7) Promotion (promosi)

Kegiatan promosi yang dilakukan adalah dengan bersosialisai ke SMA-SMA, melalui Alumni yang ada di Su,bawa, Bima,Daompu Dan lombik dan juga melalui alternative lainya

8) People (Sumber Daya Manusia)

Sebuah perguruan tinggi akan makin menonjol di masyarakat apabila memiliki tenaga dosen-dosen ahli di bidangnya . Kualitas dosen dari Fakultas FISIP sudah sangat bagus dapat dilihat dari jenjang pendidkannya yaitu setara (S2) dari masing-masing jurusan dan dilihat juga dari hasil karya dosen-dosennya seperti berikut :

2. Mengidentifikasi pasar (Calon mahasiswa) yang dituju

Pelaksanaan promosi melibatkan beberapa tahap yang salah satunya adalah dengan mengidentifikasi pasar (Calon Mahasiswa) yang dituju.mHasil wawancara dengan ketua program studi dan wakil dekan FISIPOL mengenai sasaran promosi FISIPOL adalah sebagai berikut:

"Mahasiswa Universitas Muhammadyah Mataram lebih banyak dari suku mbojo dari pada sasak di karenakan tipelogi mazhab. Jamaah NW (Nahdatul Wathan) terbesar berada di Lombok, jadi biasanya mereka mengambil pendidikan pada kampus yang tidak berlawanan dengan mazhabnya tapi tahun ini juga jumlah mahasiswa dari sini sudah meningkat". (Hasil wawancara dengan dekan FISIP, Drs. M. Junadin, MM).

Tim promosi tahun 2016/2017 menyebar personilnya untuk melakukan promosi diseluruh Kabupaten dan Kota di NTB secara merata sehingga memperoleh hasil yang sangat mengembirakan.

"Dari hasil wawancara tersebut mahasiswa mengatakan alasanya memilih FISIPOL Universitas 
Muhamadiyah mataram (UMM) karena guru di sekolahnya merekomendasikannya untuk melanjutkan studi di Universitas muhammadyah Mataram, adanya brosur yang menjelaskan keunggulan program studi, fasilitas dan kualifikasi dosen".

Kesimpulan dari informasi tersebut dapat ditarik kesimpulan siswa tamatan SMTA memilih masuk kuliah di FISIPOL disebabkan Kualitas dosen, sarana prasarana penunjang proses pembelajaran sangat representatif.

3. Strategi Promosi FISIPOL Dalam meningkatkan Jumlah Mahasiswa

Promosi adalah merupakan salah satu elemen dalam marketing mix yang sangat penting dilakukan oleh FISIPOL dalam pemasaran jasa pendidikan. Jadi promosi merupakan salah satu aspek yang penting dalam manajemen pemasaran dan sering dikatakan sebagai proses berlanjut. Dengan promosi menyebabkan orang yang sebelumnya tidak tertarik untuk masuk ke FISIPOL akan menjadi tertarik dan memilih FISIPOL sebagai tempat kuliah.

Kesimpulan menggunakan strategi promosi langsung ke lokasi lebih efektif dan perlu dilakukan secara terus menerus karena strategi ini sangat efektif untuk mendapatkan mahasiswa baru.

Berdasarkan hasil wawancara dengan Wakil Dekan FISIPOL Universitas Muhammadyah Mataram Drs. M. Junaidin, MM. Mengatakan :

"Pentingnya strategi promosi dilakukan karena tidak sedikit calon mahasisiswa yang masih bingung mau melanjutkan kemana, jadi melalui promosi itu juga kita dari pihak fakultas maupun universitas mengkomunikasikan keunggulankeunggulan fakultas dan mengenalkan jurusan dan program studi yang ada di FISIP”.

Berdasarkan hasil wawancara dengan koordinator promosi Dedy Iswanto, ST.,MM Menyatakan:

"Kegiatan promosi yang ada hampir semua dari Universitas, kami yang disini dilibatkan dalam pelaksanaanya. Perumusan kegiatan dari sana, misalnya seperti sosialisasi ke SMA-SMA, melalui alumni yang ada di sumbawa, Bima, Dompu dan Lombok, kami berangkat dengan tim promosi Universitas. Kalau yang dilakukan di tingkat fakultas sendiri memang ada tapi sebagai pelengkap promosi pihak universitas".

Tim promosi Universitas dan tim promosi Fakultas sebenarnya memiliki tujuan yang sama yaitu sebagai suatu langkah informatif dan persuasif untuk menarik minat calon mahasiswa baru, perbedaanya terletak pada spesifikasi tim promosi fakultas yang mempromosikan program studi di FISIPOL lebih intensif dan spesifik, sementara tim promosi Universitas untuk mempromosikan semua Fakultas di Universitas Muhammadyah Mataram secara keseluruhan, namun keterlibatan dosen FISIPOL sebagai anggota seksi promosi tingkat Universitas yang akan mempromosikan FISIPOL secara spesifik dapat dikatakan sebagai bentuk kerja sama FISIPOL dengan Universitas dalam mempromosikan FISIPOL.
Adapun strategi promosi yang dilakukan fakultas

FISIPOL adalah:

1. Periklanan (advertising)

Periklanan adalah segala bentuk penyajian non personal dan promosi ide, baran atau jasa oleh suatu sponsor tertentu memerlukan pembayaran. Dalam periklanan media penyampaian pesan memang peranan penting dalam proses komunikasi. Media periklanan meliputi segenap perangkat yang dapat memuat atau membawa pesan-pesan penjualan kepada calon mahasiswa.

"untuk penyebaran brosur, kami juga melibatkan dan fokus pada mahasiswa dengan menitipkan brosur kepada mahasiswa yang pulang ke kampung halaman agar dibagikan kepada keluarga atau temanya yang akan melanjutkan kuliah". (hasil wawancara dengan ketua program studi ilmu Administrasi bisnis, Lalu Hendra Maniza, S.Sos, MM).

Jadi kesimpulannya promosi yang dilakukan dengan cara strategi fokus pada daerah-daerah yang banyak anak tamatan SMTA menjadi mahasiswa FISIPOL pada tahun sebelumnya.

Strategi daya tarik digunakan fakultas FISIPOL secara empirik

Dapat dilihat dalam iklan yang menonjolkan daya tarik berupa:

a. Gedung bertingkat

b. Price advertising yaitu menonjolkan harga yang menarik

c. Dosen-dosen senior yang berpengalaman

d. Laboratorium komputer

e. Ditunjang oleh perpustakaan yang lengkap

f. Praktek magang di instansi pemerinya maupun swasta

g. Beasiswa PPA dan BBM

h. Sistem pembelajaran dengan student centered learning

i. Akses internet gratis

4. Promosi Pemasaran (Promotion marketing)

Promosi pemasaran adalah bentuk persuasi langsung yang memulai penggunaan berbagai insentif yang dapat diatur untuk merangsang minat calon mahasiswa dengan segera dan/atau meningkatkan jumlah mahasiswa yang masuk kuliah.

FISIPOL Universitas Muhammadiyah Mataram juga melakukan strategi promosi pemasaran untuk meningkatkan minat calon mahasiswa baru, yaitu:

a. Menawarkan keringanan uang sumbangan dan pembangunan bagi calon mahasiswa yang berasal dari SMA/SMK Muhammadiyah.

b. Penawaran beasiswa PPA dan BBM.

c. Lulus tanpa tes untuk calon mahasiswa yang mendaftar paling awal sampai batas tanggal yang ditentukan.

5. Pemasaran Langsung (Direct Marketing)

Direct Marketing adalah penggunaan surat, telepon, faksimil, e-mail dan alat penghubung non personal lain untuk komunikasi secara langsung dengan atau mendapatkan tanggapan langsung dari calon mahasiswa.

Dalam strategi pemasaran langsung, FISIPOL Universitas Muhammadiyah Mataram melakukan 3 teknik promosi yaitu: 
a. Bekerja sama dengan SMA/SMK Muhammadiyah turut mempromosikan Universitas Muhammadiyah Mataram dengan cara merekomendasikan Universitas Muhammadiyah Mataram sebagai alternativ tempat melanjutkan kuliah kepada siswa.

b. Bersurat ke SMA/SMK Sasaran

Dari hasil wawancara terhadap Dekan FISIPOL bahwa FISIP bersurat kepada sekolah-sekolah sebagai upaya promosinya.

c. Presentase di sekolah.

Tim promosi FISIPOL bersama-sama dengan tim promosi Universitas melakukan road show ke SMA/Sederajat yang ada di NTB, program promosi ini biasanya dilakukan 3 bulan sebelum Ujian Nasional berlangsung dengan meminta izin terlebih dahulu pada kepala sekolah dan Dinas Pendidikan.

d. Hubungan Masyarakat (Public Relation)

Hubungan masyarakat merupakan upaya komunikasi dari suatu lembaga untuk mempengaruhi persepsi, opini, keyakinan dan sikap berbagai kelompok terhadap perusahaan tersebut.

Keberhasilan perguruan Tinggi Swasta mengangkat citranya, diharapkan dapat mempengaruhi persepsi dan menghasilkan“image builuing"calon terhadap Universitas Muhammadiyah Mataram khususnya FISIPOL.

Dalam upaya meningkatkan akuntabilitas, FISIPOL meningkatkan partisipasi masyarakat dalam pengelolaannya, karena pada dasarnya hakekat lembaga pendidikan adalah ingin melayani dan di cari masyarakat. Oleh karena itu, FISIPOL menggalakan pengabdian pada masyarakat, dosen dengan melibatkan sejumlah mahasiswa, terutama dalam pelaksanaan KKN (Kuliah Kerja Nyata)

e. Pemasaran Perseorangan (Personal Marketing) Personal marketing adalah interaksi antar individu, saling bertemu muka yang ditujukan untuk menciptakan, memperbaiki, menguasai, atau mempertahankan hubungan pertukaran yang saling menguntungkan dengan pihak lain. Penjualan perseorangan segala bentuk aktivitas akademika FISIPOL baik terancam maupun tidak terancam yang juga dilakukan oleh mahasiswa dan alumni dalam mengenalkan FISIPOL secara tatap muka dengan calon mahasiswa, adapun yang termasuk dalam strategi penjualan pribadi yang dilakukan oleh FISIPOL adalah:

1) Alumni FISIPOL

Peran alumni sangat efektif untuk merekrut calon mahasiswa baru, kegiatan-kegiatan yang dilakukan oleh alumni baik secara individual maupun organisasi akan meningkatkan nama baik FISIPOL. Kegiatan pelacak kadang perekaman data lulusan/alumni dilakukan terpusat oleh unit lembaga pada tingkat Universitas tersebut Keluarga Alumni Universitas Muhammadiyah Mataram (KAUM).

\section{KESIMPULAN DAN SARAN}

\section{Kesimpulan}

Keberhasilan Fakultas Ilmu Sosial dan Ilmu Politik (FISIPOL) dalam meningkatkan jumlah mahasiswa tidak terlepas dari promosi yang dilakukan. Adapun kesimpulan dari hasil penelitian "strategi promosi dalam meningkatkan jumlah mahasiswa baru FISIP Universitas Muhammadiyah Mataram" adalah: Strategi promosi yang digunakan Fakultas FISIP dalam meningkatkan jumlah mahasiswa baru adalah sebagai berikut:

a. Strategi periklanan melalui media cetak, media elektronik dan media luar ruang.

b. Strategi promosi penjualan yaitu dengan menawarkan keringanan pembayaran uang sumbangan dan pembangunan bagi calon mahasiswa yang berasal dari SMA/SMK Muhammadiyah, penawaran beasiswa dan free test untuk calon mahasiswa yang mendaftar lebih awal sampai deadline yang ditentukan.

c. Strategi pemasaran langsung yaitu dengan cara bekerja sama dengan SMA/SMK Muhammadiyah, presentasi ke sekolah-sekolah dan bersurat ke sekolah sasaran.

\section{Saran}

a. Jenis program studi yang dimiliki oleh FISIP sangat berpengaruh dalam menarik calon mahasiswa oleh karena itu, Fakultas perlu membentuk tim promosi yang berkerlanjutan yang terdiri dari mahasiswa, alumni agar promosi lebih efektif karena masyarakat pada umumnya masih kurang mengetahui dengan program studi yang ada di Fakultas FISIPOL.

b. Meningkatkan sarana dan prasarana seperti kondisi ruang kelas yang lebih, bersih, nyaman dan lain-lain.

c. Diharapkan kepada Dosen-Dosen pengajar agar melanjutkan jenjang pendidikannya ke jenjang S3 yang linear dan bagi karyawan dapat melanjutkan pada jenjang pendidikan $\mathrm{S} 1, \mathrm{~S} 2$ 


\section{DAFTAR RUJUKAN}

[1] Fred R. David (ed), Manajemen Strategis Konsep, Edisi 10, diterjemahkan oleh Ichsan Seryobudi, Jakarta: Salemba Empat, 2006.

[2] http://www.kejujuran.click/2015/10/KomponenKomponen-Marketing-MixLengkap.html?m=l

[3] Kotler, Philip, Manajemen Pemasaran, Edisi Milenium, Jakarta, Prehallindo, 2000.

[4] Kotler, Philip, Manajemen Pemasaran, Jilid 1, Edisi Milenium, Jakarta, Prehallindo, 2002.

[5] Kotler, Philip, dan Gary Amstrong. Prinsip-Prinsip Pemasaran.Alih Bahasa Imam Nurmawan.Jakarta : Penerbit Salemba Empat. 2001.

[6] Lamb, Hair, dan McDaniel. 2001. Pemasaran. Buku1. Penerjemah David Octarevia. Jakarta: Penerbit Salemba Empat.

[7] Lamb, Hair, dan McDaniel. 2001. Pemasaran. Buku2. Penerjemah David Octarevia. Jakarta: Penerbit Salemba Empat

[8] Lupioyadi, Rambat. 2001, Manajemen Pemasaran Jasa.Jakarta Penerbit Salemba Empat.

[9] Michael E. Porter, Strategi Bersaing, Tehnik Menganalisis Industry dan Pesaing, Jakarta: Erlangga, 2001, hal 35.

[10] Michael E. Porter, Strategi Bersaing, Tehnik Menganalisis Industry dan Pesaing, Jakarta: Erlangga, 2001, hal 16.

[11] Michael E. Porter, Strategi Bersaing (competitive Strategy), Tanggerang: Kharisma Publishing Grup, 2007.

[12] Moekijat.Manajemen Pemasaran. Bandung : Penerbit Mandar Maju.200o.

[13] Philip, Kotler, Prisip-Prinsip Pemasaran (edisi kedelapan, jilid 1), Jakarta: Erlangga, 2001.

[14] Sigit, Suhardi. Marketing Praktis. Cetakan Pertama. Yogyakarta:Penerbit Liberty, 2007.

[15] Solihin, Ismail, Manajemen Strategik, Bandung: Penerbit Erlangga, 2012.

[16] Sugiyono. 2012. Metode Penelitian Kuantitatif Kualitatif dan R\&B. Bandung: Alfabeta.

[17] Swasta, Basu dan Irawan.Manajemen Pemasaran Modern. Edisi II Yogyakarta: Liberty, 2008. 